\section{Discussion}

Jaundiced sera from infants with hyperbilirubinaemia and artificially jaundiced model sera showed maximum absorption of light between 450 and $460 \mathrm{~nm}^{2}$ which agrees closely with the observations that blue light in this range is most efficacious in photodegradation of bilirubin. ${ }^{3}$ The effeet of photodegradation of bilirubin in vivo is well known, and there is evidence that the in vitro serum model has the same reaction, provided that a physiological solution is used. ${ }^{4}$ The jaundiced model sera used in this study contained appropriate amounts of albumin and remained well within the bilirubin-stable $\mathrm{pH}$ required and should have reflected the in vivo state.

Fig. 1 shows that the decline of bilirubin in white light was less effective than that of a combination of white and blue tubes, or pure blue only. There appears to be no advantage in using four blue tubes as opposed to a combination of two blue and two white tubes. Intense blue light is not liked by the staff of neonatal nurseries as it can cause nausea, headaches, and dizziness ${ }^{5}$ it also gives the baby an abnormal colour, making the detection of cyanosis difficult. The combination of blue and white light gives the infant a more acceptable colour and disturbs the staff less.

The Vickers phototherapy unit is clearly better at degrading bilirubin. Less light energy in the measured range is required to produce the same effect in decline of bilirubin. The principle of exposing any patient to the lowest possible radiation, even if the radiation is in the form of light energy, is an important one. The complications of phototherapy include potential long-term harm, and accurate recordings of periods of exposure to light and the radiant flux of the light energy should be made.

There is a linear relationship between bilirubin breakdown and the degree of light energy used in clinical phototherapy. ${ }^{6}$ The Air-Shields unit however provides more light energy in the $450 \mathrm{~nm}$ wavelength than the Vickers for the all blue, and blue and white combinations. The degree of bilirubin breakdown however is no better than the Vickers unit, suggesting that another wavelength may also be contributing to the bilirubin decay. A small absorption peak at $420 \mathrm{~nm}$ has been found in jaundiced neonatal skin ${ }^{7}$ and this may account for this disparity. It has not been possible to measure and compare the emission spectra of the two units to see if the Vickers device has a broader range over the wider bilirubinsensitive spectrum.

We thank Dr Herbert Barrie for practical help.

\section{References}

1 Ente G, Lanning E W, Cukor P, Klein R M. Chemical variables and new lamps in phototherapy. Pediatr Res $1972 ; 6: 246-51$.

2 Blondheim S H, Lathrop D, Zabriskie J. Effect of light on the absorption spectrum of jaundiced serum. J Lab Clin Med 1962; 60: 31-9.

3 Bonta B W, Warshaw J B. Importance of radiant flux in the treatment of hyperbilirubinemia: failure of overhead phototherapy units in intensive care units. Pediatrics 1976; 57: 502-5.

4 Sisson T R C, Kendall N, Davies R E, Berger D. Factors influencing the effectiveness of phototherapy in neonatal hyperbilirubinemia. Birth Defects 1970; 6: No. 2, 100-5.

5 Sisson T R C, Kendall N. Letter: Avoidance of undesirable effects of blue light in phototherapy. J Pediatr 1973; 82: $163-4$.

- Mims L C, Estrada M, Gooden D S, Caldwell R R, Kotas R V. Phototherapy for neonatal hyperbilirubinemia -a dose response relationship. J Pediatr 1973; 83: 658-62.

7 Rubaltelli F F, Carli M. The effect of light on cutaneous bilirubin. Biol Neonate 1971; 18: 457-62.

Correspondence to Dr M I Levene, Institute of Child Health, Hammersmith Hospital, Du Cane Road, London W12 0HS.

\title{
Acute water intoxication as another unusual manifestation of child abuse
}

\section{J G MORTIMER}

Department of Paediatrics and Child Health, University of Otago Medical School, Dunedin, New Zealand

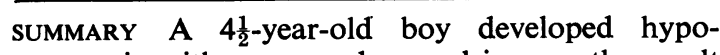
natraemia with coma and convulsions as the result of acute water intoxication. Information subsequently obtained strongly suggested that the excessive water ingestion was enforced by a punitive foster father.
It is known that child abuse can take many different forms. Kempe ${ }^{1}$ listed some of the rarer manifestations of this disorder and asked that others should be reported so as to improve clinical acumen in this difficult field. He quoted, among other manifestations, hypernatraemic dehydration in older children, caused by a psychotic parent withholding 
water to decrease urine production and stop bed wetting. In this report, a child developed hyponatraemia as a consequence of acute water intoxication, probably the result of water ingestion enforced by a punitive foster parent.

\section{Case report}

A boy of $4 \frac{1}{2}$ was brought to hospital in coma with generalised tonic-clonic seizures. The antecedent history was obtained from his foster parents who had been looking after him for 7 months. They reported that he had a craving for fluid and an excessive urinary output, and that he drank from any source, including flower pots and beer bottles. On the day of admission he had been drinking from a water hose. Early in the evening he had vomited and passed one diarrhoeal stool. Shortly after this he was found in coma with facial twitching and generalised rigidity.

On initial assessment he was in a deep coma with no response to painful stimuli. He was hypothermic with a rectal temperature of $33^{\circ} \mathrm{C}$. There was evidence of multiple injuries. The right arm was in plaster for a 2-week-old supracondylar fracture. There was a bruise over the left temporal region and multiple linear bruises on the posterior aspect of the thighs, buttocks, and lower lumbar region. There was no evidence of internal or visceral damage, nor was there evidence of dehydration, blood loss, or circulatory collapse.

Further questioning of the parents revealed that the elbow fracture supposedly followed a fall, and that the bruising was the result of chastisement with a willow stick. Two explanations for the chastisement were given. One, that the child had defecated on the bedroom carpet, and the other that he had drunk water out of a concrete mixer.

Despite the external bruising, there was no evidence of intracranial trauma. Skull $x$-ray showed no fractures and no signs of raised intracranial pressure. Lumbar puncture yielded a normal cerebrospinal fluid (the cerebrospinal fluid pressure was not measured). Serum sodium was $117 \mathrm{mmol} / \mathrm{l}$, and potassium $3.2 \mathrm{mmol} / \mathrm{l}$; blood urea $6.3 \mathrm{mmol} / 1$ $(37.9 \mathrm{mg} / 100 \mathrm{ml})$, blood glucose $10 \mathrm{mmol} / 1(180$ $\mathrm{mg} / 100 \mathrm{ml}$ ), urine specific gravity 1002 , ketones +++ , no sugar.

Skeletal survey revealed the healing supracondylar fracture of the right humerus, only. Plain films of the abdomen showed considerable distension of the stomach.

The diagnostic possibilities included: diabetes mellitus, diabetes insipidus, adrenocortical insufficiency, intrinsic renal disease, and acute water intoxication. The only disorder which fitted all the findings appeared to be acute water intoxication.

The child was treated with rewarming, intravenous diazepam (5 mg, two doses), and water restriction. A pronounced diuresis ensued with successive urine specimens showing specific gravities of 1002 , 1005,1005 , and 1007. Gradually the frequency of urinary voiding decreased. Approximately 8 hours after admission he regained consciousness, but complained of headache. Thereafter, apart from some minor vomiting he made a steady and complete recovery. The next day the serum electrolytes, blood glucose, blood urea, urine analysis, and specific gravity were all normal.

As there was clear evidence of mismanagement and maltreatment by his foster parents, the child was moved to new foster parents. When the boy was discharged from hospital the reason for the episode of acute water intoxication was still unclear; the tentative supposition was that the child had developed compulsive water drinking as a reaction to prolonged emotional deprivation. When seen subsequently, with a new foster mother, he remained well. There was no polydipsia or polyuria. Later the child said that he had not drunk the water voluntarily but that, 'Johnny forced the hose in my mouth and made me drink the water'. Johnny was the previous foster father who had admitted thrashing the child with a willow stick. When he was later asked his views on physical punishment of children, he stated that the use of the willow stick was not excessive, and that when he, himself, had been a child he had been punished with a stock whip. Despite these and other statements in his own defence, the foster father was subsequently prosecuted and convicted on a charge of assault against the child.

\section{Discussion}

Although there was evidence that this child was the victim of deliberate physical injury, there was no evidence of intracranial injury and the reason for his presentation in coma with seizures was at first obscure. The demonstration of severe hyponatraemia was the clue, which led to a careful consideration of the possible causes of hyponatraemia and the subsequent recognition of acute water intoxication as the primary event.

Symptomatic water intoxication is not unusual when fluids are given involuntarily via the gastrointestinal tract, and has been reported after gastric lavages and enemas. ${ }^{2}$

If the child has pre-existing renal disease then a sudden water load is especially dangerous as hypo- 
natraemia develops with great rapidity, and seizures and coma can quickly supervene. ${ }^{3}$

In a review of 'abuse dwarfism'4 it was noted that the characteristic features of psychosocial deprivation might include, among others, "A history of unusual eating and drinking behaviour, reversible on change of domicile, such as eating from a garbage can and drinking from a lavatory, polydipsia and polyphagia, enuresis and encopresis, and pathological family relationships, including unusual cruelty and neglect, either somatic or psychic, or both'.

Although this child was not dwarfed the events reported include many of the behavioural signs Money listed. ${ }^{4}$ However, it remains unclear whether the acute water intoxication was the result of voluntary excessive drinking as a manifestation of deprivation or starvation or, as the child stated, was because of forced water ingestion from the hose inserted in his mouth. The latter seems a more probable, albeit bizarre, explanation. Presumably if water is forcibly introduced into the oral cavity by hose the victim has only two options. Either he inhales the water with the probability of drowning or he swallows the water with the consequence of acute water intoxication. We suggest that forced water intoxication be added to the growing list of rare manifestations of child abuse.

\section{References}

1 Kempe C H. Uncommon manifestations of the battered child syndrome. Am J Dis Child 1975; 129 : 1265.

2 Dugan S, Holliday M A. Water intoxication after voluntary fluid ingestion. Pediatr 1967; 39: 418-20.

3 Kohn B, Norman M E, Feldman H, Thier S O, Singer I. Hysterical polydipsia (compulsive water drinking) in children. Am J Dis Child 1976; 130: 210-2.

4 Money J. The syndrome of abuse dwarfism (psychosocial dwarfism or reversible hyposomatotropism). Am J Dis Child 1977; 131 : 508-513.

Correspondence to Professor J G Mortimer, Department of Paediatrics and Child Health, University of Otago Medical School, PO Box 913, Dunedin, New Zealand.

\section{Hypoxia in a neonate caused by intermittent positive pressure ventilation}

\section{R BEDDIS AND M SILVERMAN}

\section{Department of Paediatrics and Neonatal Medicine, Hammersmith Hospital, London}

SUMMARY A newborn baby receiving mechanical ventilation was noted to have an extremely variable degree of hypoxia, despite the administration of $100 \%$ oxygen. The hypoxia was relieved rapidly when mechanical ventilation was withdrawn.

Although intermittent positive pressure ventilation (IPPV) may improve arterial oxygenation it may also cause a number of adverse haemodynamic effects, notably an increase in pulmonary vascular resistance and a decrease in cardiac output. ${ }^{1}$ In the neonate an increase in pulmonary vascular resistance may result in extrapulmonary right-to-left shunts through the foramen ovale and ductus arteriosus.

We report a case in which hypoxia occurred during unnecessary IPPV of a neonate. The hypoxia improved and the fractional inspired oxygen $\left(\mathrm{F}_{1} \mathrm{O}_{2}\right)$ concentration was greatly reduced when IPPV was stopped.

\section{Case report}

A boy weighing $1290 \mathrm{~g}$ was born at another hospital by assisted breech delivery with forceps applied to the aftercoming head, after spontaneous onset of labour at 29 weeks' gestation. The Apgar score at one minute was 5 ; only pharyngeal suction and oxygen administration via face mask were required. Grunting and subsostal recession were noted from birth and although he was nursed in $50 \%$ oxygen, neither blood-gas measurements nor a chest $x$-ray was done at this stage. At $\mathbf{3 0}$ minutes the baby's colour was poor and IPPV was started by oro-tracheal tube, with $100 \%$ oxygen at pressures of $20 / 0 \mathrm{cmH}_{2} \mathrm{O}$ (peak airways pressure/end expiratory pressure). His condition improved and from $1 \frac{1}{2}$ hours he was ventilated using intermittent mandatory ventilation at 7 breaths $/ \mathrm{min}$.

On transfer to Hammersmith Hospital at 3 hours ventilation was continued at $15 / 0 \quad \mathrm{cmH}_{2} \mathrm{O}, 30$ breaths/min, and 1:1 inspiratory:expiratory (I:E) ratio. These settings were maintained until $10 \mathrm{~min}$ before mechanical ventilation was stopped. Arterial oxygen tension $\left(\mathrm{PaO}_{2}\right)$ was monitored by an umbilical arterial catheter-tip oxygen electrode (Searle) and it was noted that there were wide fluctuations in $\mathrm{PaO}_{2}$. This was confirmed by monitoring transcutaneous oxygen tension $\left(\mathrm{TcPo}_{2}\right)$ (Radiometer): recordings were made on a chart recorder (Devices). 